\title{
Human altruistic tendencies vary with both the costliness of selfless acts and socioeconomic status
}

\author{
Cyril Grueter ${ }^{\text {Corresp., }}{ }^{1}$ ， Jesse A Ingram ${ }^{1}$ ， James W Lewisson ${ }^{1}$ ， Olivia R Bradford ${ }^{1}$ ， Melody Taba ${ }^{1}$, Rebecca E \\ Coetzee $^{1}$, Michelle A Sherwood ${ }^{1}$ \\ ${ }^{1}$ Anatomy, Physiology and Human Biology, University of Western Australia, Perth, Western Australia, Australia \\ Corresponding Author: Cyril Grueter \\ Email address: cyril.grueter@uwa.edu.au
}

Altruism toward strangers is considered a defining feature of humans. However, manifestation of this behaviour is contingent on the costliness of the selfless act. The extent of altruistic tendencies also varies cross-culturally, being more common in societies with higher levels of market integration. However, the existence of local variation in selfless behaviour within populations has received relatively little empirical attention. Using a 'lost letter' design, we dropped 300 letters (half of them stamped, half of them unstamped) in 15 residential suburbs of the greater Perth area that differ markedly in socioeconomic status. The number of returned letters was used as evidence of altruistic behaviour. Costliness was assessed by comparing return rates for stamped vs unstamped letters. We predicted that there is a positive association between suburb socioeconomic status and number of letters returned and that altruistic acts decrease in frequency when costs increase, even minimally. Both predictions were solidly supported and demonstrate that socioeconomic deprivation and elevated performance costs independently impinge on the universality of altruistic behaviour in humans. 
1 Human altruistic tendencies vary with both the costliness of selfless acts

2 and socioeconomic status

3

4 Cyril C. Grueter ${ }^{1}$, Jesse A. Ingram ${ }^{1}$, James W. Lewisson ${ }^{1}$, Olivia R, Bradford ${ }^{1}$, Melody Taba ${ }^{1}$,

5 Rebecca E. Coetzee ${ }^{1}, \&$ Michelle A. Sherwood ${ }^{1}$

6

$7{ }^{1}$ School of Anatomy, Physiology and Human Biology, The University of Western Australia,

8 Crawley (Perth), 35 Stirling Highway, WA 6009, Australia; e-mail address:

9 cyril.grueter@uwa.edu.au (corresponding author)

11 Word count: 3640

12

13

14

15

16

17

18 
Abstract

21 Altruism toward strangers is considered a defining feature of humans. However, manifestation of this behaviour is contingent on the costliness of the selfless act. Evidence shows that the extent of altruistic tendencies also varies cross-culturally, being more common in societies with higher levels of market integration. However, the existence of

25 local variation in selfless behaviour within populations has received relatively little empirical attention. Using a 'lost letter' design, we dropped 300 letters (half of them stamped, half of them unstamped) in 15 residential suburbs of the greater Perth area that differ markedly in socioeconomic status. The number of returned letters was used as evidence of altruistic behaviour. Costliness was assessed by comparing return rates for stamped vs unstamped letters. We predicted that there is a positive association between suburb socioeconomic status and number of letters returned and that altruistic acts decrease in frequency when costs increase, even minimally. Both predictions were solidly supported and demonstrate that socioeconomic deprivation and elevated performance costs independently impinge on the universality of altruistic behaviour in humans. 


\section{Introduction}

42 Prosocial sentiments, i.e. caring about the welfare of others, have emerged as hallmarks of humans (Gintis 2003; Henrich et al. 2004; Hill et al. 2009; Alvard 2012); but see (BurtonChellew \& West 2013). Altruism represents a special case of prosociality in which an actor helps others at a personal cost. Altruism can become fixed in stable groups of humans and other animals through kin selection, a process whereby individuals accrue indirect benefits through the successful reproduction of relatives (Hamilton 1964). Explaining altruism directed at unrelated individuals requires the framework of direct reciprocity (Trivers 1971) or indirect reciprocity (Alexander 1987). In direct reciprocity, the temporary costs individuals incur by performing an 'altruistic' act will be recouped by subsequent generosity on the part of the recipient. In indirect reciprocity, lending a helping hand can enhance the reputation of individuals and increase the likelihood of others cooperating with them in the future.

However, when altruism surfaces in large anonymous groups of unrelated individuals canonical evolutionary approaches based on nepotistic biases, direct reciprocity and indirect reciprocity can largely be ruled out as explanations . It has been argued that largescale cooperation can be maintained when behaviourally rather homogenous groups of prosocial individuals gain a competitive edge against groups of less prosocially cohesive individuals (cultural groups selection) (Henrich 2004; Richerson et al. 2016; but see Yamagishi and Mifune 2015). 
63 Despite its ubiquity in human societies, the propensity for altruism varies and is expected

64 to be superseded by selfish motives when acts of altruism are more costly, that is when

65 they entail larger sacrifices to one's own payoff (Fehr \& Fischbacher 2003). This argument

66 has been substantiated through economic games such as the dictator game, e.g. when the

67 cost of relinquishing one monetary unit to the recipient increases, the dictator donates less

68 (Andreoni \& Miller 2002). In a study using children it was shown that in a costly sharing

69 game (when delivering rewards to a recipient required personal sacrifice) the likelihood of

70 prosocial behaviour was lower than in a prosocial game (in which offering a reward to a

71 recipient had no inherent costs) (House et al. 2013). Further evidence for cost-dependent

72 variation in altruism is presented by Stewart-Williams (2007) who used questionnaires

73 about help exchanged with individuals of different relatedness classes and found that with

74 increasing costs of help, nonkin received a smaller share of the help given than kin.

Prosocial inclinations are also contingent on the social and ecological environment (Lamba

77 \& Mace 2011). House et al. (2013) demonstrated the emergence of population-specific variation in costly prosociality during middle childhood. A cross-cultural study of behaviour in ultimatum games showed that levels of prosociality increased with market integration and the reliance on cooperative partners from outside the immediate family (Henrich et al. 2005; Henrich et al. 2010). However, the existence of local variation in prosocial behaviour within such industrialized populations has received relatively little empirical attention (but see Wilson et al. 2009; Nettle et al. 2011; Holland et al. 2012; Silva \& Mace 2014, 2015). 
85 A simple but powerful way to quantify pure altruism toward strangers in a naturalistic

86

87

88

89

90

91 setting (urban context) is through the lost letter experiment. This experiment involves dropping letters on the sidewalk and counting the number of letters that are picked up by passers-by and mailed to the addressee (Milgram et al. 1965). Previous applications of this methodology have found that letter return rates were correlated with perceived neighbourhood quality (Wilson et al. 2009) and objective neighbourhood wealth and socioeconomic status (Nettle et al. 2011; Holland et al. 2012; Silva \& Mace 2014).

In the present study we aim to apply the lost letter technique to simultaneously disentangle the effects of both socioeconomic status and the inherent costs of executing a task on the prevalence of altruistic behaviour in an urban setting. We first predicted that spontaneous prosociality would be less prevalent in areas of low socioeconomic status because poorer neighborhoods are characterized by low neighbourhood quality (Wilson et al. 2009), high crime rates (Sampson et al. 1997; Nettle et al. 2011), low social capital and trust (Sampson et al. 1997; Li et al. 2005; Nettle et al. 2011), and low rates of civic engagement (Li et al. 2005). Hence letters dropped in socioeconomically poorer areas should have a lower likelihood of being returned. We also predicted that increased costs of returning the letter would decrease altruism (Fessler 2009). That is, among the returned letters there would be fewer unstamped letters; due to the additional financial expense required to post an unstamped letter, it can be implied that returning unstamped letters imposes a larger cost to the actor.

\section{Methods}

2.1 Data collection 
108 We (the authors) dropped a total of 300 letters (150 stamped and 150 unstamped) were 109 dropped in 15 residential suburbs in the Perth Metropolitan area that differed in levels of 110 socioeconomic deprivation/affluence. We distributed twenty letters, ten stamped and ten 111 unstamped, face up on sidewalks of each suburb. We addressed envelopes to one of the 112 author's home address; we did not drop any letters in the suburb that the letters were 113 addressed to. We chose the addressee's name to be 'S. Roberts', as we considered it to be a 114 gender-neutral name. We chose a 'Western' name to remove any potential ethnic biases 115 (Ahmed 2010). There was no 'return to sender' address. We addressed all the letters in the 116 same handwriting in the same standard white envelope. Since the letter was handwritten, 117 it can be deduced that the letter did not contain official documents, utility bills or company 118 letters. The content of the letter was a folded piece of A4 paper containing the name of the 119 suburb the letter was dropped in and a note on whether it was stamped or unstamped. The 120 content of the letter was indistinguishable from the outside.

121 We dropped all 300 letters in their respective suburbs on the same evening between 17:00 122 and 19:00. We dropped the letters on a Saturday evening to ensure no postmen would pick 123 up the letters, as they do not work until Monday morning. We dropped the letters 124 strategically dropped on a weekend that had no rain forecasted to avoid damage to the 125 letters. We dropped the letters approximately 5 meters from a house driveway or front 126 gate on the pedestrian walkway to ensure visibility. We did not drop any letters in front of 127 any of the small businesses that exist in the residential suburbs, and also avoided 128 construction sites. This increased the likelihood of the letters being returned by actual 129 members of the area rather than short-term visitors. We did not drop any letters in sight of 130 a post box or post office so as to make it more likely that the effort the finder would have to 
131 go to was roughly consistent across suburbs. There was only a maximum of one letter in

132 each street to maximize the spread of the letters within the suburb, which reduced the

133 likelihood of a participant coming across more than one letter and potentially alerting them

134 to the nature of the experiment.

135 Ethics approval for the above project was granted in accordance with the requirements of

136 the National Statement on Ethical Conduct in Human Research and the policies and

137 procedures of The University of Western Australia (RA/4/1/7801).

$139 \quad 2.2$ Data analysis

140 Suburbs were classified according their economic status. The Socio-economic Indexes for 141 Areas (SEIFA) was used to determine the socioeconomic status of the different suburbs in 142 which the letters were distributed. Specifically, the Index of Relative Socioeconomic 143 Disadvantage (IRSD) was used which ranks areas on a scale from most disadvantaged to

144 least disadvantaged. The index takes into account 16 different variables from the 2011 145 census data, with each variable receiving a different weighting. Some of the more heavily

146 weighted variables included the percentages of low-income houses, jobless parents,

147 individuals living without internet and other variables including education level, 148 occupation and average rent (Australian Bureau of Statistics 2009, 2014). These variables 149 are combined to produce a decile ranking of deprivation for specific areas, on a scale of 1 to 15010 (henceforth termed socioeconomic index). A score of 1 for an area shows that the 151 residents in that area are in the most disadvantaged 10\% in the nation. Some suburbs are 152 composed of smaller statistical areas; for these suburbs the median rating of deprivation 153 was taken (Supplemental File 1). Suburbs characterized by large socioeconomic variation 
154 (difference between maximum and minimum IRSD for statistical areas $>300$ ) were not

155 included in the experiment.

156 We first ran a Generalized Linear Mixed Model with binomial error structure and logit link

157 function using the glmer function from the lme4 package (Bates et al. 2015) in R (R

158 Development Core Team 2014) version 3.1.0. The response variable - letter returned vs.

159 not returned - was binary. Fixed effects were socioeconomic status, and whether or not a

160 letter was stamped or unstamped. We also included number of postboxes in a suburb as a

161 control variable. Suburb was classified as a random effect and included in the statistical

162 model. Next, using a likelihood ratio test, we compared a saturated model containing all

163 fixed effects with a null model containing none of the fixed effects but the same random

164 effect as the saturated model (Forstmeier \& Schielzeth 2011). The interaction between

165 stamped/unstamped and socioeconomic status was not significant and was therefore not

166 retained in the final model. P-values for individual predictors were calculated based on

167 Satterthwate's approximations using the lmerTest package (Kuznetsova et al. 2014).

\section{Results}

A total of 92 stamped and 46 unstamped letters were returned (Supplemental Files 1, 2). A comparison of the full model to the null model showed that the set of predictors had a

172 strong effect on whether a letter would be returned or not $\left(\chi^{2}=45.373, p<0.001\right)$. An analysis of the individual predictors in the model showed that unstamped letters had a

174 significantly lower chance of being returned (estimate $=-0.320, \mathrm{SE}=0.054, \mathrm{p}<0.001$ ) (Fig.

175 1). Socioeconomic index also had a significant effect on whether or not a letter was 
176 returned (estimate $=0.035, \mathrm{SE}=0.011, \mathrm{p}=0.00167$ ) (Fig. 2). A confounding effect of

177 density of postboxes could be ruled out (estimate $=-0.002, \mathrm{SE}=0.012, \mathrm{p}=0.919$ ).

\section{4. Discussion}

A steady stream of recent research has undermined the original characterization of

humans as Homines economici by uncovering substantial levels of prosocial behaviour

(Gintis 2003; Henrich et al. 2004; Hill et al. 2009; Alvard 2012). The present field

experiment using lost letters demonstrating people's willingness to engage in truly altruistic acts conforms with this paradigm. However, our experimental approach has revealed that these altruistic tendencies vary strongly with both levels of neighborhood socioeconomic status and the costs involved in performing the altruistic act. Cost of the act has rarely been investigated within this experimental paradigm. When there was the likely added cost of going to a post office and purchasing a stamp, a letter was roughly half as likely to be returned. This is in line with results from economic games (Isaac \& Walker 1988; Andreoni \& Miller 2002), questionnaire-based studies on helping behaviour

191 (Stewart-Williams 2007) and two earlier implementations of the lost letter experiment

192 (one of which was not couched in an evolutionary framework) (Simon 1971; Fessler 2009). 193 The negative effect of low socioeconomic status on letter return rates is in agreement with 194 most studies that utilized the lost letter technique to measure altruism.

195 The lower level of altruistic behaviour evident in poorer suburbs has been suggested to be 196 a consequence of individual or neighborhood characteristics associated with 197 socioeconomic deprivation (Holland et al. 2012). Individuals facing financial hardship, poor 
198 health and general life instability are likely to be preoccupied with achieving immediate

199 needs, leaving less time and effort available to spend on benefiting a stranger (Lynam et al.

200 2000; Holland et al. 2012). In contrast, resource-rich individuals are not likely to be

201 affected by such time and financial constraints. Individuals residing in poorer

202 neighborhoods are also less likely to be embedded in a socially cohesive and supportive

203 network and are exposed to higher levels of crime, conditions that discourage the

204 development of trust required for civic efforts and prosociality (Holland et al. 2012).

205 Wilson et al. (2009) found a good match between individual prosociality and the quality of

206 the neighborhood (or more specifically the prosociality of the individuals' social

207 environment) and reasoned that "this empirical result explains why it is possible for

208 prosociality to succeed as a behavioural strategy in contemporary human life. Very simply,

209 those who give to others also get from others." (p. 198).

One mechanism by which altruistic behaviour to unrelated individuals can be explained is

212 reputation enhancement (Nowak \& Sigmund 2005). In our study, a number of the returned envelopes were annotated, detailing that the person had found and returned the letter on

214 their own goodwill. In one instance, the mobile phone number of the finder was written on 215 the envelope. In addition, one letter was hand delivered to the addressee's house. These 216 actions suggest that the actors desired recognition of their good deed, supporting the 217 theory of reputation enhancement.

218 Overall, our findings show that the willingness of individuals within a community to be 219 altruistic decreases with increasing costs and social disadvantage. More broadly, this 
220 research shows that ecological variation within a given population can evoke divergent

221 patterns of helping behaviour. In the context of business and industry, these results can aid

222 charities and other crowd-funded organizations in directing their efforts to where they will

223 likely receive the greatest return. Data such as the ones collected in this study provide a

224 reflection of community attitudes and may therefore prove relevant to municipal

225 government for policy development and intervention.

226

\section{5. Acknowledgments}

228 We thank David Coall for helpful comments on this paper.

\section{References}

231

232

233

234

235

236

237

238

Ahmed, A. M. (2010). Muslim discrimination: Evidence from two lost letter experiments. Journal of Applied Social Psychology, 40, 888-98.

Alexander, R. D. (1987) The biology of moral systems. Carmel, IN: Hawthorne.

Alvard, M. (2012) Human sociality. In Mitani, J. C., Call, J., Kappeler, P., Palombit, R. A. \& Silk, J. B. (Ed.), Evolution of primate societies (pp. 585-603). Chicago: University of Chicago Press.

Andreoni, J. \& Miller, J. (2002). Giving according to Garp: an experimental test of the consistency of preferences for altruism. Econometrica 70, 737-53. 
239 Australian Bureau of Statistics (2009) Information Paper: An Introduction to Socio-

$240 \quad$ Economic Indexes for Areas (SEIFA), 2006.

241 http://www.abs.gov.au/ausstats/abs@.nsf/mf/2039.0.

242

Australian Bureau of Statistics (2014). Census of Population and Housing: Socio-Economic Indexes for Areas (SEIFA), Australia, 2011. http://www.abs.gov.au/ausstats/abs@.nsf/Lookup/2033.0.55.001main\%2Bfeature s100042011.

Bates D., Maechler, M., Bolker, B. \& Walker, S. (2015). Fitting linear mixed-effects models using lme4. Journal of Statistical Software, 67, 1-48..

Burton-Chellew, M. N. \& West, S. A. (2013). Prosocial preferences do not explain human cooperation in public-goods games. Proceedings of the National Academy of Sciences 110, 216-21.

Fehr, E. \& Fischbacher U. (2003). The nature of human altruism. Nature 425, 785-91.

Fessler, D. M. T. (2009). Return of the lost letter: Experimental framing does not enhance altruism in an everyday context. Journal of Economic Behavior \& Organization 71, $575-578$.

Forstmeier, W. \& Schielzeth, H. (2011). Cryptic multiple hypotheses testing in linear models: overestimated effect sizes and the winner's curse. Behavioural Ecology and Sociobiology 65, 47-55.

Gintis, H. (2003) Solving the puzzle of prosociality. Rationality and Society 15, 155-87.

Hamilton, W. D. (1964) The genetical evolution of social behaviour. I. II. Journal of Theoretical Biology 7, 1-52. 
261 Henrich, J. (2004) Cultural group selection, coevolutionary processes and large-scale

262

263

264

265

266

267

268

269

270

271

272

273

274

275

276

277

278

279

280

281

282 cooperation. Journal of Economic Behavior \& Organization 53, 3-35.

Henrich, J., Boyd, R., Bowles, S., Camerer, C., Fehr, E. \& Gintis, H. (2004) Foundations of human sociality: Economic experiments and ethnographic evidence from fifteen small-scale societies. Oxford University Press.

Henrich, J., Boyd, R., Bowles, S., Camerer, C., Fehr, E., Gintis, H., McElreath, R., Alvard, M., Barr, A. \& Ensminger, J. (2005) “Economic man” in cross-cultural perspective: Behavioural experiments in 15 small-scale societies. Behavioural and Brain Sciences $28,795-815$.

Henrich, J., Ensimger, J., McElreath, R., Barr, A., Barrett, C. Bolyanatz A., Cardenas J.C., Gurven M., Gwako E., Henrich N., Lesorogol C., Marlowe F., Tracer D. \& Ziker J. (2010) Markets, religion, community size, and the evolution of fairness and punishment. Science 327, 1480-4.

Hill K., Barton M. \& Hurtado A.M. (2009) The emergence of human uniqueness: characters underlying behavioural modernity. Evolutionary Anhropology 18, 187-200.

Holland J., Silva, A. S. \& Mace, R. (2012) Lost letter measure of variation in altruistic behaviour in 20 neighbourhoods. PLOS ONE 7, e43294.

House B. R., Silk J. B., Henrich J., Barrett H. C., Scelza B., Boyette A., Hewlett B. \& Laurence S. (2013) The ontogeny of prosocial behaviour across diverse cultures. Proceedings of the National Academy of Sciences 110, 14 586-14 591.

Isaac R. M. \& Walker J.M. (1988) Group size effects in public-goods provision: the voluntary contributions mechanism. Quarterly Journal of Economics 103, 179-99. 
283 Kuznetsova A., Brockhoff P.B. \& Bojesen Christensen R.H. (2014) lmerTest: Tests for

284

285

286

287

288

289

290

291

292

293

294

295

296

297

298

299

300

301

302

303

304

305

random and fixed effects for linear mixed effect models (lmer objects of lme4 package). https://cran.r-project.org/web/packages/lmerTest/index.html.

Lamba S. \& Mace R. (2011) Demography and ecology drive variation cooperation across human populations. Proceedings of the National Academy of Sciences 108, 1442630.

Li Y., Pickles A. \& Savage M. (2005) Social capital and social trust in Britain. European Sociological Review 21, 109-23.

Lynam D.R., Caspi A., Moffit T.E., Wikström P.O. \& Loeber R., \& Novak, S. (2000) The interaction between impulsivity and neighborhood context on offending: The effects of impulsivity are stronger in poorer neighborhoods. Journal of Abnormal Psychology 109, 563.

Milgram S., Mann L. \& Harter S. (1965) The lost-letter technique: a tool of social research. Public Opinion Quarterly 29, 437.

Nettle D., Colléony A. \& Cockerill M. (2011) Variation in cooperative behaviour within a single city. PLOS ONE 6, e26922.

Nowak M.A. \& Sigmund K. (2005) Evolution of indirect reciprocity. Nature 437, 1291-8.

Richerson P., Baldini R., Bell A.V., Demps K., Frost K., Hillis V., Mathew S., Newton E.K., Naar N., Newson L., Ross C., Smaldino P.E., Waring T.M. \& Zefferma M. (2016) Cultural group selection plays an essential role in explaining human cooperation: A sketch of the evidence. Behavioral and Brain Sciences 39, e30.

Sampson R.J., Raudenbush S.W. \& Earls F. (1997) Neighborhoods and violent crime: A multilevel study of collective efficacy. Science 277, 918-24. 
306 Silva A.S. \& Mace R. (2014) Cooperation and conflict: field experiments in Northern Ireland. 307 Proceedings of the Royal Society of London B: Biological Sciences 281, 20141435.

308 Silva A.S. \& Mace R (2015) Inter-group conflict and cooperation: field experiments before, 309 during and after sectarian riots in Northern Ireland. Frontiers in Psychology 6, 1790.Simon W.E. (1971) Return rates of "lost" letters as a function of whether the

Stewart-Williams, S. (2007). Altruism among kin vs. nonkin: effects of cost of help and reciprocal exchange. Evolution and Human Behaviour 28, 193-8.

R Development Core Team (2014). R: A language and environment for statistical

Yamagishi T. \& Mifune N. (2016). Parochial altruism: does it explain modern human group

Wilson, D. S., O’Brien, D. T. \& Sesma, A. (2009). Human prosociality from an evolutionary perspective: variation and correlations at a city-wide scale. Evolution and Human

Trivers, R. L. (1971). The evolution of reciprocal altruism. The Quarterly Review of Biology computing. Vienna, Austria: R Foundation for Statistical Computing. $46,35-57$. Behaviour 30, 190-200.

324

325 


\section{Figure captions}

329 Figure 1: Mosaic plot illustrating the percentage of returned letters as a function of whether 330 they were stamped (Yes) or unstamped (No).

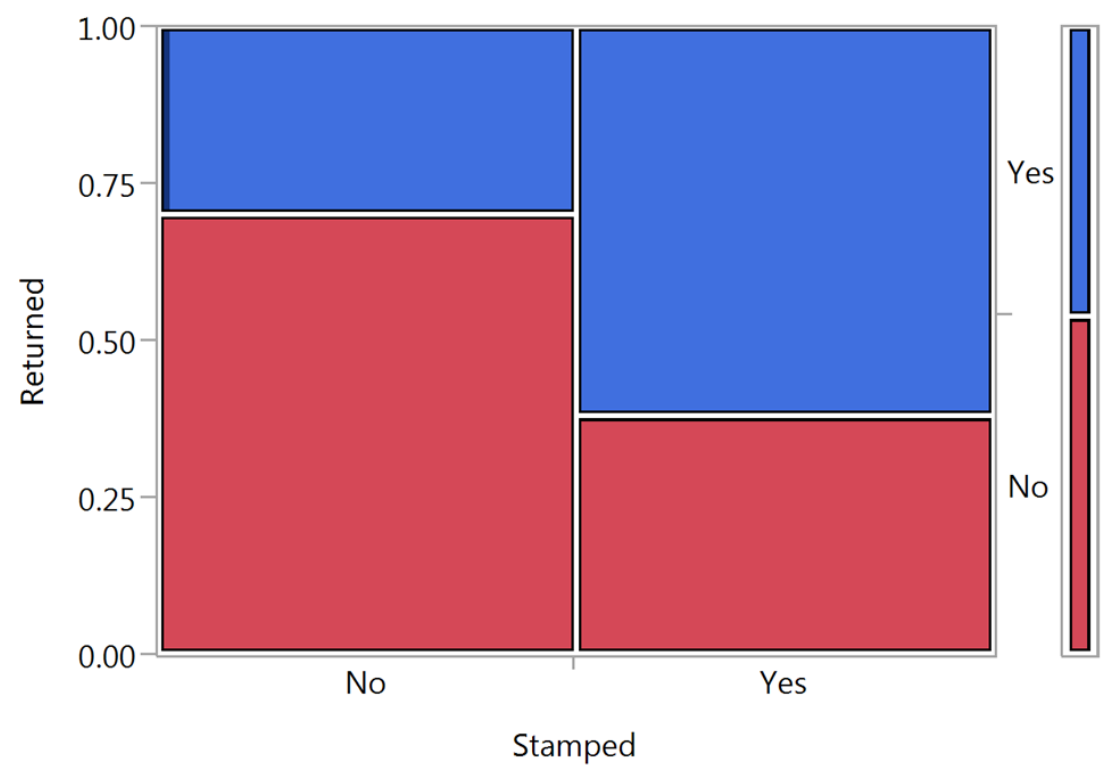

332

333

334

335

336

337

338 
Figure 2: Visualization of the effect of socioeconomic index (SEI) on whether a letter was

342 returned or not (dichotomous variable). Letters dropped in high (10) SEI suburbs were

343 more likely to be returned. The blue line represents a cut-point and not a trend line.

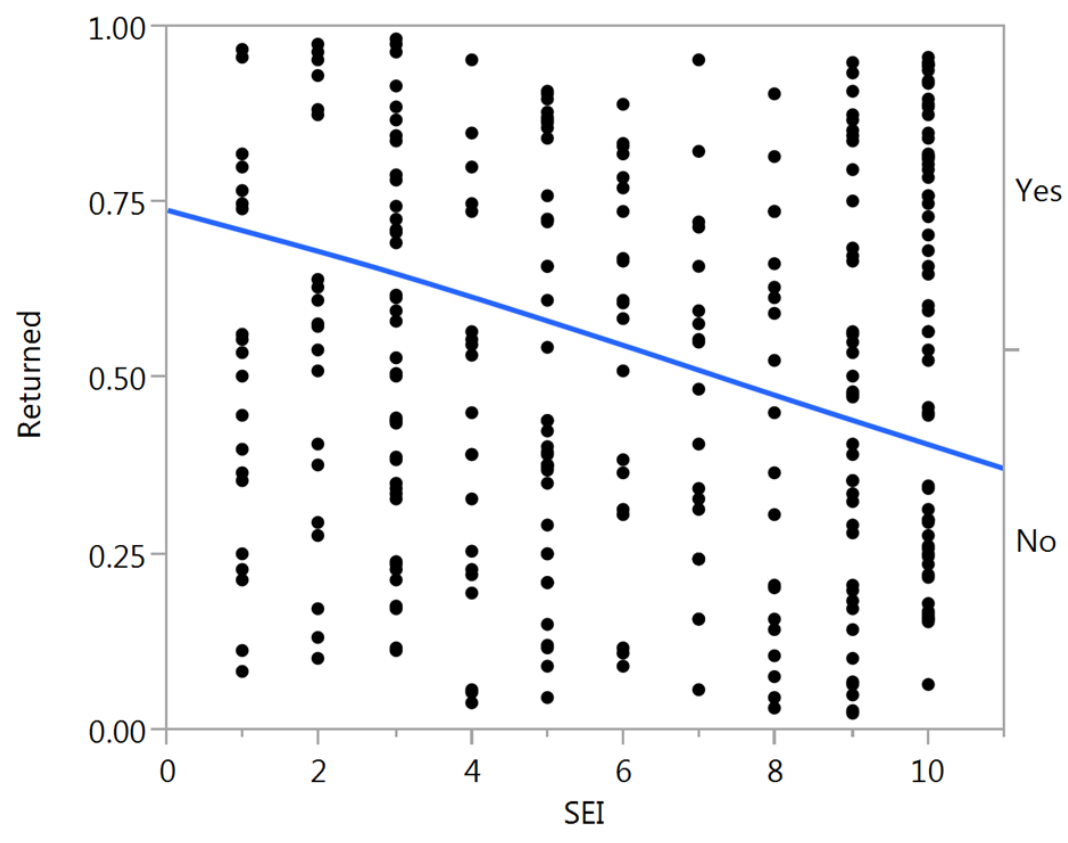

344 